\title{
Identification and evaluation of agents isolated from traditionally used herbs against Ophiophagus hannah venom
} \author{
Eric Lattmann ${ }^{1, *}$ \\ ${ }^{1}$ Division of Pharmacy, School of Life and Health Sciences, Aston University, Birmingham, England; \\ ${ }^{2}$ Department of Pharmacology, Faculty of Medicine, Khon Kaen University, Khon Kaen, Thailand; \\ ${ }^{3}$ Department of Biochemistry, Faculty of Science, Khon Kaen University, Khon Kaen, Thailand.
}

Rima Salama ${ }^{1}$, Jintana Sattayasai ${ }^{2}$, Arun Kumar Gande ${ }^{1}$, Nison Sattayasai ${ }^{3}$, Mike Davis ${ }^{1}$,

\begin{abstract}
The aim of this study was firstly to identify active molecules in herbs, that are traditionally used for the treatment of snake bite, such as Curcuma antinaia, Curcuma contravenenum, Andrographis paniculata, and Tanacetum parthenium; secondly to test similar structurally related molecules and finally to prepare and evaluate an efficient formulation against Ophiophagus hannah venom intoxification. Three labdane based compounds, including labdane dialdehyde, labdane lactone, and labdane trialdehyde and two lactones including 14-deoxy-11,12-didehydroandrographolide and parthenolide were isolated by column chromatography and characterised. Using the isolated rat phrenic nerve-hemidiaphragm preparation, the antagonistic effect of crude extracts, isolated compounds and prepared formulations were measured in vitro on the inhibition of the neuromuscular transmission. Inhibition on muscle contraction, produced by the $5 \mu \mathrm{g} / \mathrm{mL}$ venom, was reversed by test agents in organ bath preparations. $A$ labdane trialdehyde, isolated from $C$. contravenenum, was identified as the best antagonising agent in the low micromolar range. Tests on formulations of the most potent $C$. contravenenum extract showed, that the suppository with witepsol H15 was an effective medicine against $O$. hannah venom. This study elucidated the active compounds, accounting for the antivenin activity of traditionally used herbs and suggested the most suitable formulation, which may help to develop potent medicines for the treatment of snake bite in the future.
\end{abstract}

Keywords: Antivenin activity, rat nerve-hemidiapragm, labdane dialdehyde, labdane trialdehyde, parthenolide, desoxy-andrographolide

\footnotetext{
*Address correspondence to:

Dr. Eric Lattmann, Division of Pharmacy, School of Life and Health Sciences, Aston University, Aston Triangle, Birmingham B4 7ET, England.

E-mail: e.lattmann@aston.ac.uk
}

\section{Introduction}

The actual incidence and the severity of snake poisoning are currently highly undervalued (1). The importance of snake bites is considered a major occupational disease causing both disabilities and mortalities. This disease is causing devastation to individuals, who are involved in agricultural work in the tropical regions worldwide. Inaccurate epidemiological data resulted in the underestimation of this international problem, which requires both high attention and sincere efforts to alleviate its burden (2). Based on these facts, the World Health Organization (WHO) is calling for new, proven and affordable treatments. Traditional medicine or herbal medicine has long been used for the treatment of snake bite worldwide for its affirmed effectiveness, easy availability, and fine economic affordability. However, the active ingredients contained in these herbs and most effective formulations are still needed to be elucidated.

We have previously reported a labdane dialdehyde structure (Figure 1), which was isolated from a novel Curcuma zedoaroides species and exhibited well antivenin activity (3). Species in the genus Curcuma including Curcuma antinaia and Curcuma contravenenum were in regular use in Thailand against cobra intoxication, but they are very hard to find on local markets in Isarn today. Besides of those herbs, another two medical plants including Andrographis paniculata and Tanacetum parthenium are widely applied for the treatment of snake bite in India and China. Andrographis paniculata is in use in India as a snake venom antidote.

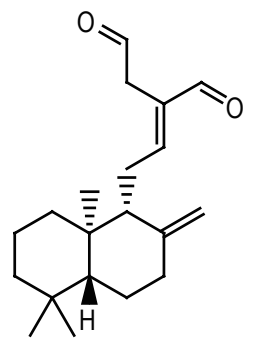

Figure 1. Chemical structure of labdane dialdehyde. 
The leaves of $A$. paniculata, locally known as Nilavembu, were grinded into a paste and applied topically at the site of the snake's bite (4). Tanacetum parthenium, a member of the Asteraceae family, which is also known as the Compositae family, represents a herb well known for its medicinal properties. Since ancient times this herb was used by the Greeks and the Egyptians as well as the early Europeans for the treatment of a number of illnesses, such as headaches, stomach ache, menstrual pain, joint pain, fever. The Chinese used this herb due to its healing properties against insects and snake bites (5). In order to further elucidate the ingredients, that account for antivenin activity of these herbs and develop formulations, that are effective against snake venom, we prepared and tested the in vitro antivenin activity of the crude extracts, purified compounds and certain formulations against Ophiophagus hannah venom in the present study.

\section{Materials and Methods}

\subsection{Materials}

Lyophilized $O$. hannah venom was obtained from the Queen Suavabha Memorial Institute, Bangkok, Thailand. The venom was dissolved in normal saline, aliquoted and kept at $-20^{\circ} \mathrm{C}$ as stock solution. Herbs including C. zedoaroides, C. antinaia, C. contravenenum, A. paniculata, and T. parthenium were purchased from the King Cobra Village, Khon Kaen Province, Thailand. The chemicals and solvents were purchased from Aldrich (Gillingham, UK) and Lancaster Synthesis (Lancaster, UK). Mass spectra were obtained by Atmospheric Pressure Chemical Ionisation (APCI), using a HewlettPackard 5989b quadrupole instrument (Vienna, Austria). Both proton and carbon NMR spectra were obtained on a Brucker AC 250 instrument (Follanden, Switzerland), calibrated with the solvent reference peak. Infra-red spectra were plotted from $\mathrm{KBr}$ discs on a Mattson 300 FTIR spectrophotometer (Coventry, UK).

Laboratory and HPLC grade dichloromethane, petroleum ether $60-80^{\circ} \mathrm{C}$, ethyl acetate, chloroform-d and methanol were purchased from Fisher-Scientific (Waltham, MA, USA). The Soxhlet extraction system was the Quickfit (C5/23) model with (24/29) joint from BÜCHI, Switzerland. The heating mantle used was the Heidolph EKT 3001 from Sigma-Aldrich, UK. The rotary evaporator used was the BÜCHI Rotavapor Model R-144, Switzerland. ${ }^{1} \mathrm{H}-\mathrm{NMR}$ and ${ }^{13} \mathrm{C}-\mathrm{NMR}$ were recorded in Bruker advance 400 in chloroform-d. Column chromatography was carried out on silica gel and thinlayer chromatography (TLC) on TLC-silica gel $60 \mathrm{~F}_{254}$.

\subsection{Preparation of crude extracts and isolation of the tested compounds}

The rhizomes of $C$. zedoaroides, $C$. antinaia, and $C$. contravenenum (30 $\mathrm{g}$ of the dried, powdered rhizomes) were extracted with dichloromethane using a Soxhlet extraction apparatus, respectively. Once the Soxhlet extractions were completed the solvent was removed under reduced pressure from the round bottom flasks using a rotary evaporator. The extract content of C. zedoaroides, C. antinaia, and C. contravenenum were gathered and the entry code Kae1, Mia3, and Rat7 was assigned. Column chromoatography of the crude extract was performed using petroleum ether:ethyl acetate (60:40) as solvent system and the compounds were detected with UV light, permanganate, and 2,4-dinitrophenylhydrazine (DNPH). The Kae1 extract finally provided labdane dialdehyde; Mia3 extract finally provided labdane dialdehyde and labdane lactone; Rat7 extract finally provided labdane dialdehyde, labdane lactone, and labdane trialdehyde. The spectra data of these three compounds are shown in the Appendix.

Fifty grams of dried and ground leaves of $A$. paniculata were extracted with $500 \mathrm{~mL}$ of methanol using to a Soxhlet extractor. The solvent was evaporated off solvent using rotary evaporation. TLC analysis was performed with a dichloromethane:methanol (95:5) solvent mixture, and both andrographolide and 14-deoxy-11,12didehydroandrographolide, were purified by column chromatography. The spectra data of 14-deoxy-11,12didehydroandrographolide are shown in the Appendix.

Fifty grams of grinded plant material $T$. parthenium was extracted with $500 \mathrm{~mL}$ of chloroform using a Soxhlet extractor. The extraction was monitored by TLC with ethyl acetate:petroleum ether $60-80^{\circ} \mathrm{C}$ (70:30) and the TLC plate was developed with vanillin reagent and heated at $400^{\circ} \mathrm{C}$ for $1 \mathrm{~min}$. Two point five gram of crude extract was dissolved in a minimum volume of ethyl acetate in the heat and $1 / 3$ of the volume of petrol ether was added and cooled on ice. The yellowish sample was recrystallised from ethyl acetate:petroleum ether (70:30) to give parthenolide, $130 \mathrm{mg}$, as an off white powder. The spectra data of this compound are shown in the Appendix.

\subsection{Preparation of C. contravenemum formulations}

Ethanolic solution (entry code: OHRat7): For the preparation of the ethanolic solution, $0.5 \mathrm{~g}$ of the concentrated extract of $C$. contravenemum was dissolved in $5 \mathrm{~mL}$ of ethanol and divided into two portions of $2.5 \mathrm{~mL}$ each. To one of the samples OHRat7 3 drops of trifluoroacetic acid were added. Both samples were incubated at $36^{\circ} \mathrm{C}$ for a period of 1 week, then tested.

Water for injection (entry code: AqRat7): For the preparation of a solution for the injection, 2.5 equivalents of an aqueous solution of $10 \% \mathrm{Na}_{2} \mathrm{~S}_{2} \mathrm{O}_{5}$ to $0.2 \mathrm{~g}$ of the extract in $0.1 \mathrm{~mL}$ DMSO were mixed until homogenous and water was added until a final volume of $4 \mathrm{~mL}$.

Suppositories (entry code: $\boldsymbol{R a t} \mathbf{S}$ ) : Suppositories (3 g) containing $30 \%$ active ingredients were prepared by the fusion method as previously described (6). Sixty six grams of $C$. contravenemum rhizomes, giving $1.98 \mathrm{~g}$ crude extract, were extracted with $300 \mathrm{~mL}$ of acetone as described. The 
Table 1. Antivenin activity of crude extracts from Curcuma species

\begin{tabular}{|c|c|c|c|c|}
\hline Entry Code & Source & Yield & Composition & Muscle contraction response \\
\hline Kae1 & C. zedoaroides & $7.0 \%$ & Labdane dialdehyde, $79 \%$ & $32.1 \%(50 \mu \mathrm{g} / \mathrm{mL}) ; 63.1 \%(100 \mu \mathrm{g} / \mathrm{mL})$ \\
\hline Mia3 & C. antinaia & $2.6 \%$ & $\begin{array}{l}\text { Labdane dialdehyde, } 45 \% \\
\text { Labdane lactone, } 39 \%\end{array}$ & $26.4 \%(50 \mu \mathrm{g} / \mathrm{mL}) ; 56.5 \%(100 \mu \mathrm{g} / \mathrm{mL})$ \\
\hline Rat7 & C. contravenenum & $3.0 \%$ & $\begin{array}{l}\text { Labdane dialdehyde, } 32 \% \\
\text { Labdane lactone, } 37 \% \\
\text { Labdane trialdehyde, } 8 \%\end{array}$ & $53.5 \%(50 \mu \mathrm{g} / \mathrm{mL}) ; 82.6 \%(100 \mu \mathrm{g} / \mathrm{mL})$ \\
\hline
\end{tabular}

Measurement time is $30 \mathrm{~min}$; full contraction $100 \%$, venom $0 \%$ at $5 \mu \mathrm{g} / \mathrm{mL}$.

solvent was evaporated off to about a third of the volume and $6 \mathrm{~g}$ witepsol H15, a synthetic fat was added and the complete solvent was then evaporated off in vacuum. The homogeneous melt was poured into the suppository moulds and after cooling the suppositories were obtained. The melting point of the prepared suppositories was detected at $32^{\circ} \mathrm{C}$.

\subsection{In vitro antivenin activity assay}

Spraque Dawley rats (200-250 g) were obtained from the Animal House, Faculty of Medicine, Khon Kaen University. The treatment procedures, according to current UK legislation, were approved by the bioethics committee, Faculty of Medicine, Khon Kaen University (HO 2434-76). Animals had free access to fresh water and food pellets. They were exposed to automated $12 \mathrm{~h}$ light cycles.

Rat phrenic nerve-hemidiaphragms were prepared according to the staff of the Department of Pharmacology, University of Edinburgh (1970) and the contractile responses were studied. The entire nerve-muscle preparation was submerged in $50 \mathrm{~mL}$ Kreb's solution with carbogen and the temperature was maintained at $37^{\circ} \mathrm{C}$. The phrenic nerve was stimulated with a rectangularwave pulse of $0.5 \mathrm{msec} / 0.5 \mathrm{~Hz}$ through a bipolar platinum electrode, using a Grass Model S-48 stimulator. Muscle contraction was recorded with a force transducer and Grass Polygraph recorder. The indicated doses of crude extract (Kae1, Mia3, and Rat7), test solutions of the isolated compounds in DMSO, and prepared formulations (OHRat7, AqRat7, and Rat7S) were added, respectively, to a circulating water bath at $37^{\circ} \mathrm{C}$ for $30 \mathrm{~min}$ and then venom was added and $30 \mathrm{~min}$ later the muscle contraction was accessed. Two phrenic nerve-hemidiaphragm preparations were obtained from one animal. Control, DMSO, was set to $100 \%, 5 \mu \mathrm{g} / \mathrm{mL}$ venom to $0 \%$. The $\%$ test response (muscle contraction) was measured at 30 min in presence of the test compounds and the venom. In the control group, $5 \mu \mathrm{g} / \mathrm{mL}$ venom alone gradually and completely inhibited the indirectly-evoked twitches within $30 \mathrm{~min}$ ( $0 \%$ response). In presence of the antidote the contraction remained at a certain percentage of the full contraction. This effect was used here to screen the 3 Curcuma plant extracts, the isolated compounds and the formulations of the best plant.

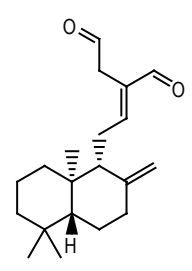

Labdane dialdehyde

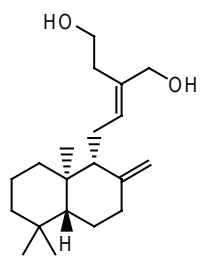$$
\text { 14-Deoxy-11,12 }
$$

Labdanediol didehydroandrographolide Parthenolide
Figure 2. Chemical structures of the isolated compounds.

\section{Results and Discussion}

\subsection{In vitro antivenin activity of crude extracts from the genus Curcuma}

The protecting effects of crude extracts Kae1, Mia3, and Rat7 from $C$. zedoaroides, $C$. antinaia, and $C$. contravenenum against $O$. hannah venom on the neuromuscular transmission of the rat phrenic nervehemidiaphragm are shown in Table 1. The Kae1 extract was obtained in the highest yield $(7 \%)$ and at a 100 $\mu \mathrm{g} / \mathrm{mL}$ dose the response was still above $60 \%$. The best protection was determined for Rat7 extract (yield 3.0\%), giving for the $100 \mu \mathrm{g} / \mathrm{mL}$ organ bath concentration a more than $80 \%$ of the original contraction of the diaphragm. Mia3 extract was obtained in the lowest yield (2.6\%) and demonstrated the lowest antivenom activity. The muscle contract response was determined as $56.5 \%$ when expososed to $100 \mu \mathrm{g} / \mathrm{mL}$ of this extract.

\subsection{Analysis of the ingredients in the crude extracts and evaluation of their antivenin activity}

The crude extracts from the five medicinal herbs, used in the present study, were further purified and generated the test compounds (Figure 2). The antivenin activities of 
these agents were examined and the results are shown in Table 2. The crude extract Kae1 from $C$. zedoaroides is a very good source of the labdane dialdehyde, which was obtained from this species in 79\% yield and excellent purity, by simple column chromatography. A $10 \mu \mathrm{g} / \mathrm{mL}$ concentration of this compound showed $83 \%$ protection against the snake venom.

The crude extract Mia3 from $C$. antinaia provided in addition to labdane dialdehyde, a second labdane derivative, identified as labdane lactone (Figure 2), which showed a bioactivity about $60 \%$. Its formation can be understand if we assume that the labdane dialdehyde is oxidised to the corresponding carboxylic acid and the second aldehyde is able to form the hydroxyl-lactone structure of labdane lactone. The proportions of labdane dialdehyde and labdane lactone in Mia3 were detected as $45 \%$ and $39 \%$, respectively. Labdane lactone was previously isolated from members of the Zingiberaceae family, which are traditionally used as a medicine against inflammatory diseases. This antiinflammatory

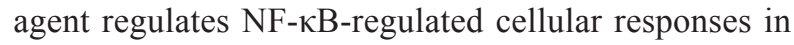
particular it inhibited NF- $\mathrm{BB}$ activation, suppressed phosphorylation, p65 nuclear translocation and reporter gene transcription (11).

From $C$. contravenenum extract Rat7, in addition to labdane dialdehyde and labdane lactone, a third molecule labdane trialdehyde (Figure 2) was finally isolated. The percentages of labdane dialdehyde, labdane lactone, and labdane trialdehyde in this extract were determined as $32 \%, 37 \%$, and $8 \%$, respectively. Labdane trialdehyde

Table 2. Antivenin activity of isolated compounds

\begin{tabular}{lc}
\hline Compound & Muscle contraction response \\
\hline Labdane dialdehyde & \\
$1 \mu \mathrm{M}$ & $66.1 \%$ \\
$10 \mu \mathrm{M}$ & $82.6 \%$ \\
Labdane diol & \\
$1 \mu \mathrm{M}$ & 0 \\
$10 \mu \mathrm{M}$ & $2.1 \%$ \\
Labdane lactone & \\
$1 \mu \mathrm{M}$ & $45.6 \%$ \\
$10 \mu \mathrm{M}$ & $61.9 \%$ \\
Labdane trialdehyde & \\
$1 \mu \mathrm{M}$ & $83.5 \%$ \\
$10 \mu \mathrm{M}$ & $99.5 \%$ \\
$14-\mathrm{Deoxy}-11,12-$ di- & \\
dehydroandrographolide & \\
$1 \mu \mathrm{M}$ & $12.2 \%$ \\
$10 \mu \mathrm{M}$ & $32.4 \%$ \\
Parthenolide & \\
$1 \mu \mathrm{M}$ & $29.4 \%$ \\
$10 \mu \mathrm{M}$ & $54.0 \%$ \\
\hline
\end{tabular}

Measurement time is $30 \mathrm{~min}$; full contraction $100 \%$, venom $0 \%$ at 5 $\mu \mathrm{g} / \mathrm{mL}$. maintained nearly a full diaphragm contraction and with $99.5 \%$ protection it is considered the best venom antidote, reported to date. Comparing the activities of these three molecules, the labdane trialdehyde is the most potent antivenin agent, followed by labdane dialdehyde and labdane lactone. Through analyzing the relationship between activities and structures of the above isolated compounds, the succindialdehyde structure may be essential and if the dialdehyde moiety was reduced to a diol the activity was lost (labdane diol, Figure 2). The labdane trialdehyde was previously isolated from myoga extracts on the search for inhibitors of human platelet aggregation and human 5-lipoxygenase. This compound was found to be a potent inhibitor of human platelet aggregation and human 5-lipoxygenase (7). The percentage, in which it is present in this curcuma species, is with $8 \%$ a good new source of this agent and therefore, it can be evaluated for further therapeutic applications.

Guided by previous enzyme-linked immunosorbent assay (ELISA) study (8) T. parthenium (Feverfew) and $A$. paniculata were also investigated in addition to the Curcuma plant. From A. paniculata, andrographolide and 14-deoxy-11,12-didehydroandrographolide were isolated and tested. The desoxy-derivative displayed a weak inhibition of $32 \%$ at the $10 \mu \mathrm{M}$ test concentration while andrographolide was found inactive as antidote. As 14-deoxy-11,12-didehydroandrographolide is only present in less than $0.01 \%$ in the traditional formulation, known as Nilavembu, it cannot be recommended. The concentration and resulting of this the active amount of 14-deoxy-11,12didehydroandrographolide is simply too low to have any medicinal effect. T. parthenium is a herb well known for its medicinal properties. The Chinese used this herb due to its healing properties against insects and snake bites. Overall parthenolide isolated from this herb had reasonable antivenom activity of about $54 \%$ and it can easily be isolated in good quantities by crystallisation. It is the only European herb, which is readily available in a commercial formulation as a tablet from e.g. simply supplements $(9)$.

\subsection{In vitro antivenin activity of $C$. contravenenum formulations}

C. contravenenum is the easiest plant in terms of plant production and has the biggest rhizome based on the total weight of the entire plant. It gave a 3.0\% yield of the crude extract (Rat7) which exhibited most potent antivenin activity. For these reasons, three formulations of Rat7 extract were prepared and tested on their antivenin activity (Table 3). The ethanolic extract of Rat7 was

Table 3. Antivenin activity of crude extracts from Curcuma species

\begin{tabular}{lll}
\hline Entry Code & Formulation & Muscle contraction response \\
\hline OHRat7 & $10 \%$ in ethanol & $1.1 \%(500 \mu \mathrm{g} / \mathrm{mL}) ; 0.2 \%(1,000 \mu \mathrm{g} / \mathrm{mL})$ \\
AqRat7 & Hydrogensulfite adduct; $5 \%$ in water & $5.1 \%(1,000 \mu \mathrm{g} / \mathrm{mL}) ; 6.3 \%(5,000 \mu \mathrm{g} / \mathrm{mL})$ \\
Rat7S & Suppository $30 \%$ & $46.1 \%(200 \mu \mathrm{g} / \mathrm{mL}) ; 77.4 \%(400 \mu \mathrm{g} / \mathrm{mL})$ \\
\hline
\end{tabular}

Measurement time is $30 \mathrm{~min}$; full contraction $100 \%$, venom $0 \%$ at $5 \mu \mathrm{g} / \mathrm{mL}$. 
found inactive, and therefore formulations in Thai whisky cannot be recommended. Chemically, the aldehyde functionality has been converted into an ethoxy semiacetale. Thus, a protected, chemically unreactive structure was formed without any bioactivity. The formulation as hydrogen sulfite adduct was supposed to work as an injection in water, but again with the loss of the chemical reactivity the bioactivity was also lost, at least in the in vitro (ex vivo) experiment. The formulation of the extract Rat 7 as a suppository worked well; in vitro $77 \%$ response remained for the $400 \mu \mathrm{g} / \mathrm{mL}$ dose, compared with the original extract of Rat7 at a $100 \mu \mathrm{g} / \mathrm{mL}$ dose, which gave $83 \%$ venom protection. Based on a good in vitro-in vivo correlation, we obtained from a previous study, 1-2 suppositories ( $3 \mathrm{~g}$ ) should translate into a working antivenom medication.

Three curcuma species, i.e. C. zedoaroides, $C$. antinaia, and $C$. contravenenum, and two other traditional medicines $A$. paniculata, and $T$. parthenium were confirmed active against $O$. hannah venom in our exvivo assay. In addition to the labdane dialdehyde, which was discovered in C. zedoaroides in our previous study, labdane lactone and labdane trialdehyde, isolated from curcuma species $C$. antinaia and $C$. contravenenum were found effective now against the venom. Labdane trialdehyde is the best anti-neurotoxic agent known to date. However, the isolated labdane trialdehyde is unstable. It is supposed, that the natural plant formulation is stabilising labdane trialdehyde with the labdane dialdehyde. Feverfew extract at high doses may be used for snake venom intoxication as a common European alternative. It should be noted, that the only efficient formulation is a suppository, in addition to the preparation of the freshly grinded root of the fresh rhizome. These results provided evidences about the usefulness of some traditional medicines as antidotes and gave clues on the drug development in the future. Further studies are ongoing to replace the in vitro antivenin assay, used in this study, by an in vitro method, in which chicken intestine is used and not laboratory animal tissue.

\section{Acknowledgements}

This study was partly supported by the Khon Kaen University Research Fund. We are grateful for the technical assistance of Wanchai Airarat.

\section{References}

1. Warrell DA. Snake bite. Lancet. 2010; 375:77-88.

2. Cruz LS, Vargas R, Lopes AA. Snakebite envenomation and death in the developing world. Ethn Dis. 2009; 19(1 Suppl 1):S1-42-46.

3. Chavaeerach A, Sudmoon R, Tanee T, Mokkamul P, Sattayasai N, Sattayasai J. Two new species of Curcuma (Zingiberaceae) used as cobra-bite antidotes. J Syst Evolut. 2008; 46:80-88.

4. Rajadurai M, Vidhya VG, Ramya M, Bhaskar A. Ethno- medicinal plants used by the traditional healers of pachamalai hills, Tamilnadu, India. Ethno-Med. 2009; 3:39-41.

5. Lee KH, Wang HK, Itokawa H, Morris-Natschke SL. Current perspectives on Chinese medicines and dietary supplements in China, Japan and United States. Yao Wu Shi Pin Fen Xi. 2000; 8:219-228.

6. Adegboye TA, Itiola OA. Physical and release properties of metronidazole suppositories. Trop J Pharm Res. 2008; 7:887-896.

7. Suebsasana S, Pongnaratorn P, Sattayasai J, Arkaravichien T, Tiamkao S, Aromdee C. Analgesic, antipyretic, antiinflammatory and toxic effects of andrographolide derivatives in experimental animals. Arch Pharm Res. 2009; 32:1191-1200.

8. Daduang S, Sattayasai N, Sattayasai J, Tophrom P, Thammathaworn A, Chaveerach A, Konkchaiyaphum M. Screening of plants containing Naja naja siamensis cobra venom inhibitory activity using modified ELISA technique. Anal Biochem. 2005; 341:316-325.

9. Kemper K. Seven herbs every paediatrician should know. Contemporary Paediatrics. 1996; 13:79-90.

10. Lattmann E, Sattayasai J, Sattayasai N, Staaf A, Phimmasone S, Schwalbe $\mathrm{CH}$, Chaveerach A. In-vitro and in-vivo antivenin activity of 2-[2-(5,5,8a-trimethyl2-methylene-decahydro-naphthalen-1-yl)-ethylidene]succinaldehyde against Ophiophagus hannah venom. J Pharm Pharmacol. 2010; 62:257-262.

11. Kunnumakkara AB, Ichikawa H, Anand P, Mohankumar CJ, Hema PS, Nair MS, Aggarwal BB. Coronarin D, a labdane diterpene, inhibits both constitutive and inducible nuclear factor- $\kappa \mathrm{B}$ pathway activation, leading to potentiation of apoptosis, inhibition of invasion, and suppression of osteoclastogenesis. Mol Cancer Ther. 2008; 7:3306-3317.

12. Tiuman TS, Ueda-Nakamura T, Garcia Cortez DA, Dias Filho BP, Morgado-Diaz JA, de Souza W, Nakamura CV. Antileishmanial activity of parthenolide, a sesquiterpene lactone isolated from Tanacetum parthenium. Antimicrob Agents Chemother. 2005; 49:176-182.

(Received January 23, 2012; Revised February 1, 2012; Accepted February 3, 2012)

\section{Appendix}

Labdane dialdehyde. 2-[2-(5,5,8a-Trimethyl-2methylene-decahydro-naphthalen-1-yl)-ethylidene]succinaldehyde. The ${ }^{1} \mathrm{H}-\mathrm{NMR}$ and ${ }^{13} \mathrm{C}$-NMR data are identical with Lattmann et al. (10).

${ }^{1} \mathrm{H}-\mathrm{NMR}\left(\mathrm{CDCl}_{3}, 300 \mathrm{MHz}\right): \delta: 9.7+9.5(1 \mathrm{H}, 1 \mathrm{H}$, $\mathrm{CHO}), 6.75(1 \mathrm{H}, \mathrm{t}, \mathrm{C} 12 \mathrm{H}), 4.90+4.40(1 \mathrm{H}, 1 \mathrm{H}, \mathrm{s}$, $\mathrm{C} 17 \mathrm{H}), 3.40(2 \mathrm{H}, \mathrm{d}, \mathrm{C} 14 \mathrm{H}), 2.40(3 \mathrm{H}, \mathrm{m}, \mathrm{C} 11 \mathrm{H}$, $\mathrm{C} 6 \mathrm{H}), 2.0-1.0(10 \mathrm{H}, \mathrm{m}), 0.9+0.8+0.7(9 \mathrm{H}, \mathrm{s}, 3 \times \mathrm{Me})$; ${ }^{13} \mathrm{C}-\mathrm{NMR}: \delta$ : 196.38, 192.60 CHO, C15 + C16; 146.96, 133.78 C8, C13, 159.05 C12, 106.33 C17, 55.20, 54.18 C6, C7, 32.22, 39.34 C1, C5, 34.15, 23.83,14.23 Me, 40.54, 38.30, 38.15, 36.78, 23.55, 23.52, 18.23 C14, C11, C9, C10, C2, C3, C4. 
Labdane lactone. 5-Hydroxy-3-[2-(5,5,8a-trimethyl2-methylene-decahydro-naphthalen-1-yl)-ethylidene]dihydro-furan-2-one. The ${ }^{1} \mathrm{H}-\mathrm{NMR}$ and ${ }^{13} \mathrm{C}-\mathrm{NMR}$ data are identical with Kunnumakkara et al. (11).

${ }^{1} \mathrm{H}-\mathrm{NMR}\left(\mathrm{CDCl}_{3}, 300 \mathrm{MHz}\right): \delta$ : 6.69 (br s, 1H), 5.94 (br s, 1H), $4.81(\mathrm{~s}, 1 \mathrm{H}), 4.36$ (br s, 1H), $2.99(\mathrm{~m}, 1 \mathrm{H}), 2.71$ $(\mathrm{m}, 1 \mathrm{H}), 2.40-2.36(\mathrm{~m}, 2 \mathrm{H}), 2.20(\mathrm{~m}, 1 \mathrm{H}), 2.05-1.08(\mathrm{~m}$, $12 \mathrm{H}), 0.89$ (s, 3H), $0.82(\mathrm{~s}, 3 \mathrm{H}), 0.71(\mathrm{~s}, 3 \mathrm{H}) ;{ }^{13} \mathrm{C}-\mathrm{NMR}$ (75 MHz): $\delta$ : 170.65, 148.01, 143.45, 124.48, 107.52, 96.46, 56.02, 55.21, 41.90, 39.94, 39.12, 37.68, 33.57, $33.45,25.58,23.99,21.62,19.21,14.23$.

Labdane trialdehyde. 2-[2-(2-Formyl-5,5,8atrimethyl-decahydro-naphthalen-1-yl)-ethylidene]succinaldehyde. The ${ }^{1} \mathrm{H}-\mathrm{NMR}$ and ${ }^{13} \mathrm{C}-\mathrm{NMR}$ data are identical with Suebsasana et al. (7).

${ }^{1} \mathrm{H}-\mathrm{NMR}\left(\mathrm{CDCl}_{3}, 300 \mathrm{MHz}\right): \delta: 9.96$ (s, 1H, H-17), 9.62 (s, 1H, H-15), 9.50 (s, 1H, H-16), 7.10 (dd, 1H, J=6.0, 8.8, H-12), 3.54 (d, 1H, $J=17, \mathrm{H}-14 \mathrm{a}), 3.48$ (d, 1H, $J=$ 17, H-14b), 2.85 (m, 1H, $J=8.8,12,15.2, \mathrm{H}-11 \mathrm{a}), 2.65$ (m, $1 \mathrm{H}, J=4,6,15.2, \mathrm{H}-11 \mathrm{~b}), 2.50$ (m, 1H, H-8), 2.35 (m, 1H, H-7b), 1.92 (m, 1H, H-5), 1.75 (m, 1H, H-1b), 1.60 (m, 2H, H-6), 1.42 (m, 1H, H-3b), 1.40 (m, 2H, H-2), 1.40 (m, 1H, H-7a), 1.22 (m, 1H, H-3a), 1.15 (m, 1H, H-1a), 1.05 (m, 1H, H-9), 0.88 (s, 2H, H-18), 0.82 (s, 3H, H-19), 0.80 (s, 3H, H-20); ${ }^{13} \mathrm{C}-\mathrm{NMR}$ (75 MHz): $\delta: 205.37$ (C-17), 198.84 (C-15), 194.80 (C-16), 158.72 (C-12), 138.35 (C-13), 56.87 (C-9), 55.03 (C-5), 49.23 (C-8), 43.16 (C-3), 40.29 (C-14), 39.88 (C-10), 39.88 (C-1), 34.25 (C-4), 34.25 (C-18), 25.65 (C-7), 27.14 (C-11), 22.31 (C-19), 20.11 (C-6), 19.82 (C-2), 16.16 (C-20).
14-Deoxy-11,12-didehydro-andrographolide. The ${ }^{1} \mathrm{H}-\mathrm{NMR}$ and ${ }^{13} \mathrm{C}-\mathrm{NMR}$ data are identical with Suebsasana et al. (7).

${ }^{1} \mathrm{H}-\mathrm{NMR}\left(\mathrm{CDCl}_{3}, 300 \mathrm{MHz}\right): \delta: 7.43(1 \mathrm{H}, \mathrm{t}, J=1.76$ $\mathrm{Hz}, \mathrm{H}-14), 6.85$ (1H, dd, $J=10.1$ and $15.8 \mathrm{~Hz}, \mathrm{H}-12)$, $6.15(1 \mathrm{H}, \mathrm{d}, J=15.8 \mathrm{~Hz}, \mathrm{H}-11), 4.86(2 \mathrm{H}, \mathrm{d}, J=1.3 \mathrm{~Hz}$, H-15), 4.75 (1H, d, $J=1.8 \mathrm{~Hz}, 17 \mathrm{a}), 4.49(1 \mathrm{H}, \mathrm{d}, J=1.8$ Hz, 17b), 4.12 (1H, d, J=11.0 Hz, H-19a), 3.39 (1H, t, $J=5.3 \mathrm{~Hz}, \mathrm{H}-3), 3.38$ (1H, d, $J=11.4 \mathrm{~Hz}, \mathrm{H}-19 \mathrm{~b}), 1.22$ (3H, s, H-18), 0.83 (3H, s, H-20); ${ }^{13} \mathrm{C}-\mathrm{NMR}: \delta: 172.2$ $(\mathrm{C}=\mathrm{O}, \mathrm{C}-16), 148.0(\mathrm{C}, \mathrm{C}-8), 142.8(\mathrm{CH}, \mathrm{C}-12), 136.0$ (CH, C-11), 129.2 (C, C-13), 121.1 (CH, C-14), 109.2 (CH2, C-17), 80.8 (CH, C-3), 69.5 (CH2, C-15), 64.2 (CH2, C-19), 61.7 (CH, C-9), 54.7 (CH, C-5), 43.0 (C, C-4), 38.5 (C, C-10), 38.2 (CH2, C-1), 36.6 (CH2, C-7), 28.1 (CH2, C-2), 22.9 (CH2, C-6), 22.6 (CH3, C-18), 15.9 (CH3, C-20).

Parthenolide. The ${ }^{1} \mathrm{H}-\mathrm{NMR}$ and ${ }^{13} \mathrm{C}-\mathrm{NMR}$ data are identical with Tiuman et al. (12).

${ }^{1} \mathrm{H}-\mathrm{NMR}\left(\mathrm{CDCl}_{3}, 300 \mathrm{MHz}\right): \delta: 6.34(\mathrm{~d}, J=3.6 \mathrm{~Hz}$,

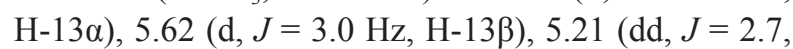
$12.0 \mathrm{~Hz}, \mathrm{H}-1), 3.86$ (t, $J=8.4 \mathrm{~Hz}, \mathrm{H}-6), 2.79$ (d, $J=9.0$ Hz, H-5), 2.74 to 2.82 (m, H-7), 2.32 to 2.44 (m, H-9ß), 2.32 to 2.49 (m, H-2 $\beta$ ), 2.11 to 2.21 (m, H-2 $\alpha, \mathrm{H}-3 \beta$,

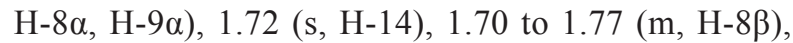
1.31 (s, H-15), 1.20 to 1.28 (m, H-3 $\alpha) .{ }^{13} \mathrm{C}-\mathrm{NMR}\left(\mathrm{CDCl}_{3}\right.$, $75.5 \mathrm{MHz}$ ): $\delta$ : 169.3 (C-12), 139.2 (C-11), 134.6 (C-10); 125.3 (C-1), 121.3 (C-13), 82.4 (C-6), 66.4 (C-5), 61.5 (C-4), 47.7 (C-7), 41.2 (C-9), 36.3 (C-3), 30.6 (C-8), 24.1 (C-2), 17.3 (C-15), 16.9 (C-14). 